\title{
Estudos da semiótica na Ciência da Informação: relatos de interdisciplinaridades
}

\section{Camila Monteiro de Barros}

\author{
Mestre em Ciência da Informação (Universidade \\ Federal de Santa Catarina).
}

Lígia Maria Arruda Café

\begin{abstract}
Doutora em Linguística (Université Laval, Canadá).Professora do Departamento de Ciência da Informação e do Programa de Pós-Graduação em Ciência da Informação da Universidade Federal de Santa Catarina, Brasil.
\end{abstract}

Semiótica e Ciência da Informação (CI) apresentam linhas interdisciplinares de estudo, uma vez que a primeira explora os processos de significação com específica propriedade e a segunda tem, nos processos de significação, um importante aspecto que impacta no dimensionamento e tratamento do seu objeto de estudo. O intuito deste artigo é investigar a interdisciplinaridade entre a Semiótica e a CI, por meio do mapeamento dos temas das duas ciências, que são postos em convergência. A pesquisa se caracteriza como bibliográfica, cujo levantamento foi realizado em periódicos brasileiros da área de $C 1$, de qualis $A 2$ a B2, no período entre 2000 e 2011. Foram recuperados 15 documentos e os resultados mostram que mais de $60 \%$ dos artigos abordam a teoria da tricotomia do signo de Peirce, sendo que quase todos os artigos abordam, de alguma forma, a noção da significação ad infinitum. No âmbito da Ciência da Informação, $60 \%$ dos artigos abordam a organização e representação do conhecimento e da informação. Conclui-se que o âmbito de estudo mais produtivo da Semiótica na CI seria aquele relacionado à organização e representação do conhecimento e, também, à organização da informação.

Palavras-chave: Semiótica; Ciência da Informação. 


\title{
Semiotics studies in the Information Science: interdisciplinarities reports
}

\begin{abstract}
Semiotics and Information Science (IS) present interdisciplinary studies since the first explores the process of signification with specific property and the second has, in the meaning process, an important aspect that impacts the dimension and treatment of its study object. The purpose of this article is to investigate the interdisciplinarity between Semiotics and IS through the mapping of the subjects, of both sciences, which are put in convergence. The research is characterized as bibliographic as the survey was made in Brazilian periodicals of IS field, quails A2-B2, between 2000 and 2011. 15 documents were retrieved and the results show that more than 60\% of the articles discuss the Peirce's trichotomy of sign theory and almost all articles discuss the notion of ad infinitum signification. In the context of IS, $60 \%$ of the articles discuss the organization and representation of knowledge and information. We conclude that the most productive study context of the Semiotics in the IS would be the one related to knowledge organization and representation and also information organization.
\end{abstract}

Key-words: Semiotics; Information Science.

Recebido em 19.04. 2012 Aceito em 02.07.2012

\section{Introdução}

A natureza é repleta de significações e o homem, por sua vez, se constitui por meio do significado (PEIRCE, 1995). Significado este que the serve como prática de reconhecimento e interação com a realidade. Textos, filmes, músicas, poemas falados, escritos ou cantados, estátuas, uma nuvem, um grito, todas essas linguagens são portadoras de significado (SANTAELLA, 2009), sendo que esse significado não é inato nas linguagens, mas parte de um processo que envolve a interpretação (ECO, 1991).

A Ciência da Informação tem, nos processos de significação, um importante aspecto que impacta no dimensionamento e tratamento do seu objeto de estudo. Esses meandros da interpretação e significação tornamse de interesse da Ciência da Informação, uma vez que ela necessita, especialmente no âmbito da organização e representação do conhecimento, interpretar e resignificar diferentes visões de mundo, que 
serão representadas por estruturas conceituais. No âmbito da organização e representação da informação, A CI desenvolve métodos para interpretar diferentes constituições textuais - nem sempre verbais -, de forma que um terceiro elemento (o usuário) esteja apto a recodificar essa interpretação, por meio de uma interpretação própria. Além das técnicas e metodologias de extração de conceitos adotados pela CI, especialmente provindas da Linguística e da Terminologia, é necessária, ainda, uma exploração de como esses processos de significação ocorrem de forma precedente à aplicação das técnicas dentro e fora do âmbito da análise documental.

Esse panorama amplo de significação é vislumbrado pela Semiótica com específica propriedade. Também, a própria formação de conceitos necessária à construção dos sistemas de organização do conhecimento e, de forma mais ampla, para o próprio processo de comunicação científica, que passa pela significação e representação do significado por um determinado signo.

Nesse sentido, o intuito deste artigo é investigar a interdisciplinaridade entre a Semiótica e a Ciência da Informação, por meio do mapeamento dos temas das duas ciências, que são postos em convergência para discussão em âmbito prático e/ou teórico.

\section{Breves esclarecimentos preliminares sobre Semiótica}

A Semiótica é a ciência que se dedica ao estudo de todos os signos, nos processos de significação na natureza e na cultura. Para Santaella (1983), a Semiótica pode ser entendida como a ciência de todas as linguagens possíveis, pois, diferentemente da Linguística, que se dedica ao estudo do sistema sígnico da linguagem verbal, a Semiótica considera qualquer fenômeno como um sistema sígnico de produção de sentido.

Diferentes autores exploram essa área do conhecimento sob perspectivas variadas. Poderíamos mencionar alguns, como Peirce, Jakobson, Morris, Greimas, Saussure, Santaella, Eco, Ogden \& Richards, Hjelmslev, Port Royal, Leibniz (NÖTH, 2003) entre tantos outros. Exploraremos, de forma muito sucinta, as concepções básicas da Semiótica de alguns desses autores. Vale ressaltar que a Semiótica é abordada em diferentes áreas do conhecimento e, por isso, não se pretende, aqui, esgotar todos os estudiosos do assunto, no entanto, como se verá mais adiante na exposição dos resultados dessa pesquisa, os autores mencionados são os mais citados nos artigos da CI, que abordam a Semiótica.

Há três grandes escolas de estudos da Semiótica (SANTAELLA, 1983; BARBALHO, 2006a). A primeira escola, que teve início na extinta União Soviética, ainda no século XIX, é representada principalmente por A. N. Viesse-Iovski, A.A. Potiebniá e Iuri Lotman. Seus estudos deram início ao estruturalismo linguístico soviético. A segunda escola tem sua base no estruturalismo linguístico francês, representada fundamentalmente pelos estudos de Saussure, Greimas e Hjelmslev, nas primeiras décadas do séc. XX. A terceira escola tem como base os estudos 
do norte-americano Peirce, que tiveram a mais forte influência na formulação dos princípios da Semiótica contemporânea, enquanto ciência dos signos.

Nesse aspecto, cabe um brevíssimo esclarecimento a respeito dos conceitos de semiótica e semiologia. Para Saussure (1975, p. 24), a língua é "um sistema de signos que exprime ideias", é uma estrutura de elementos que constitui uma instituição social e é comparável a outros sistemas significantes. Dessa forma, Saussure (1975, p. 24) admite a necessidade de uma ciência que estude "a vida dos signos no seio da vida social", a qual denominou Semiologia. Para o autor, a Semiologia estaria encarregada de entender as leis que regem os signos, leis essas que seriam aplicáveis também à Linguística.

Saussure (1975) afirma que o signo linguístico é uma entidade psíquica formada por dois elementos: o significado (conceito) e o significante (imagem acústica). Nesse sentido, o elemento da realidade ao qual o signo se refere e, portanto, externo a ele, não é considerado como parte do signo, sendo que o estudo dessa relação estaria a cargo da Semiologia. A partir dessa perspectiva, Saussure (1975) aponta que a Linguística seria uma parte dessa ciência que, para o autor, ainda estaria por existir. Eco (1991) afirma que a definição de Saussure foi muito importante para desenvolver uma consciência semiótica, sendo que a noção diática de signo antecipou as definições posteriores de função sígnica.

Nöth (2003) afirma que, por um longo período, os dois termos semiótica e semiologia - foram adotados por diferentes autores com significados ambíguos, sobrepostos ou divergentes. No entanto, em 1969, a Associação Internacional de Semiótica decidiu adotar o termo Semiótica como a ciência mais geral que estuda todos os tipos de signos e os processos de significação ou semioses, ficando a Semiologia relacionada às concepções adotadas na Linguística estruturalista da escola francesa.

A semiótica da escola francesa considera a relação diádica de significação, sobretudo dos processos de semiose humana e cultural, enquanto a escola peirceana considera todos os possíveis processos de semiose, inclusive naturais, em uma relação triádica, como veremos a seguir.

Segundo Vollis (2000), na escola de Greimas, as relações significado/significante são analisadas tanto na semântica fundamental da língua quanto no plano mais profundo do "percurso gerativo de sentido" (VOLLIS, 2000, p. 77). Nesse âmbito, a semiótica do discurso da escola greimasciana parte da análise dos conceitos por meio de oposições estabelecidas entre eles, que são organizadas pelas convenções culturais. Almeida (2009, p. 174) afirma que Greimas dedicou seus estudos a investigar os diversos tipos de textos e discursos "procurando identificar as ações que os agentes executam na dinâmica de uma narrativa".

Charles Sanders Peirce (1839-1914) é o mais importante fundador da Semiótica moderna (NÖRTH, 2003; SANTAELLA, 1983; ALMEIDA, 2009); sua teoria de proposta abrangente perpassa diversas áreas do conhecimento como a Filosofia, Fenomenologia, Pragmatismo, 
Comunicação, entre outras. Para Peirce (1995, p. 29), a Lógica "é a ciência das leis necessárias gerais dos Signos e, especialmente, dos Símbolos" e, sendo assim, o autor refere-se a esta ciência como Semiótica ou Lógica. Sua Semiótica está divida em três departamentos (PEIRCE, 1995):

a) lógica crítica: é a teoria das condições gerais de referência dos signos aos seus objetos. Santaella (2009) esclarece que a Lógica Crítica tem por objetivo investigar as condições de verdade dos argumentos, das inferências lógicas, sendo a mais complexa;

b) retórica especulativa: analisa a eficácia semiótica, ou seja, a relação dos símbolos e signos com seus interpretantes; e

c) gramática especulativa: é a parte da Semiótica peirceana que mais se difundiu (SANTAELLA, 2009) e se configura como a "doutrina das condições gerais dos símbolos e outros signos que têm o caráter significante" (PEIRCE, 1995, p. 29).

Daremos especial atenção à gramática especulativa, parte da Semiótica peirceana mais adotada nas interações e discussões da CI. Peirce, no intuito de preservar o significado dos conceitos que propôs, recorreu, muitas vezes, à criação de novos termos que representassem de forma não duvidosa tais conceitos. No capítulo "A ética da terminologia", o autor expõe: "A primeira regra de bom gosto ao escrever é usar palavras cujos significados não serão mal interpretados; e se um leitor não conhece o significado das palavras, é infinitamente melhor que ele saiba que não os conhece" (PEIRCE, 1995, p. 41). Dessa forma, no decorrer do estudo da Semiótica peirceana, é razoável o leitor se deparar com palavras desconhecidas e até, como indica Santaella (1983), estranhíssimas.

Para Peircme todas as ideias e, inclusive, o homem, são fenômenos semióticos, ou seja, todos os fenômenos no mundo estão permeados de signos, constituindo, assim, o que Nöth (2003) chama de uma "visão pansemiótica do mundo". Assim como Aristóteles, Kant e outros estudiosos, Peirce desenvolveu categorias universais, que visam a englobar todo e qualquer fenômeno do mundo. A essas categorias, Peirce chamou Primeiridade, Secundidade e Terceiridade.

A Primeiridade está relacionada com o sentimento, a consciência de um instante no tempo, "consciência passiva da qualidade, sem reconhecimento ou análise." (PEIRCE, 1995, p. 14). Santaella (1983) expõe que a primeiridade é a "qualidade de sentimento", é a primeira forma vaga e imprecisa, uma impressão imediata e indeterminada de apreensão das coisas.

A Secundidade, segundo Peirce (1995, p. 14), compreende um "sentido de resistência [da consciência], de um fato externo ou outra coisa". Para Nöth (2003, p. 64), a secundidade é a categoria da comparação, da "realidade e da experiência no tempo e no espaço". 
Segundo Santaella (1983), a secundidade é a ação cotidiana da consciência, reagindo em relação ao mundo.

A Terceiridade é a "consciência sintética, reunindo tempo, sentido de aprendizado, pensamento" (PEIRCE, 1995, p. 14). Na categoria da terceiridade, por meio do pensamento, representamos e reconhecemos o mundo, assim, acontece a relação de um fenômeno segundo, ou seja, relativo a secundidade, a um fenômeno terceiro que ocorre na camada da inteligibilidade, no pensamento em signos (NÖTH, 2003; SANTAELLA, 1983).

O homem compreende o mundo por meio de uma representação que, por sua vez, é reconhecida por outra representação, que Peirce denomina como interpretante da primeira, e, assim, ad infinitum. Peirce (1995) afirma que um signo ou representamen é algo que, sob certo aspecto, representa algo para alguém. Ou seja, para que algo seja um signo, é necessário que represente alguma outra coisa - seu objeto -, o signo dirige-se a alguém e cria na mente dessa pessoa outro signo equivalente, o interpretante. Assim, o signo existe em uma relação triádica entre objeto, signo e interpretante. Ao reconhecimento do interpretante, relaciona-se outro signo, em um entendimento de significação que está sempre em expansão, em que o significado de um pensamento ou signo é reconhecido por outro pensamento ou signo, em um processo de semiose infinita ou autogeração. Dessa forma, a primeiridade, é um quase-signo, pois, ainda, não foi articuladamente pensado, representado.

As relações que Peirce (1995) estabelece i) conforme o signo em si mesmo, ii) do signo conforme a relação com seu objeto e iii) do signo conforme a relação com a representação do interpretante, considerandose os conceitos de primeiridade, secundidade e terceiridade, resultaram nas três tricotomias do signo e nas dez classes de signos que, segundo o autor, podem sofrer ainda infinitas divisões.

Quadro 1- Tricotomia do signo de Peirce

\begin{tabular}{cc|c|c}
\hline $\begin{array}{c}\text { Signo } 1^{\mathbf{o}} \text { em si } \\
\text { mesmo }\end{array}$ & $\begin{array}{c}\text { Signo } 2^{\mathbf{o}} \text { com seu } \\
\text { objeto }\end{array}$ & $\begin{array}{c}\text { Signo } 3^{\mathbf{0}} \text { com seu } \\
\text { interpretante }\end{array}$ \\
\hline $1^{\mathbf{o}}$ & quali-signo & ícone & rema \\
\hline $2^{\mathbf{o}}$ & sin-signo & índice & dicente \\
\hline $3^{\mathbf{o}}$ & legi-signo & símbolo & argumento \\
\hline
\end{tabular}

Fonte: SANTAELLA (1983, p. 62).

As noções de signo $1^{\circ} ., 2^{\circ}$. e $3^{\circ}$. dizem respeito às categorias de primeiridade, secundidade e terceiridade. Assim, o símbolo, por exemplo, é um signo de segunda tricotomia, que participa da categoria da terceiridade. Cada tricotomia confere aos tipos de signo características que instituem a forma como se estabelecem as relações no sistema sígnico, especialmente em relação ao objeto. Dessa forma, os signos que estão para a primeiridade se relacionam ao seu objeto por meio das suas qualidades, da expressão de meras possibilidades (PEIRCE, 1972) ou no nível de raciocínio (rema), no máximo, uma hipótese (SANTAELLA, 1993). Os signos que estão para a secundidade têm uma relação existente, 
concreta, com seu objeto. Já os signos que estão para a terceiridade, têm em si mesmos um comparecimento de lei. Assim, o argumento, tipo de maior complexidade de significação, "é um Signo que se entende representar seu Objeto em seu caráter de Signo" (PEIRCE, 1972), o argumento é um signo genuíno.

A semiótica de Peirce não se resume às suas tricotomias de signo, no entanto, essas figuram como a parte de sua teoria que mais tem servido de base às discussões de conceitos e atividades subjacentes à CI, especialmente aquelas relacionadas à organização e representação do conhecimento e da informação, como será exposto mais adiante.

Lucia Santaella é professora titular da PUC-SP e, em 2007, foi eleita presidente da Charles S. Peirce Society (USA); tem diversos livros publicados que tratam do tema Semiótica, especialmente voltados para a semiótica cognitiva e computacional ${ }^{1}$. Alguns desses livros, em parceria com Winfried Nöth, na revisão, prefácio ou autoria coletiva. Nöth foi presidente da Associação Alemã de Semiótica e, na década de 1990, esteve na PUC-SP. Santaella se dedicou a estudar em detalhes a obra de Peirce, publicando livros com comentários e esclarecimentos sobre a semiótica peirceana (ALMEIDA, 2009). Seus estudos se baseiam majoritariamente na Semiótica de Peirce, com base na qual desenvolveu sua teoria das matrizes da linguagem e pensamento.

Para Santaella (2009), todas as espécies de linguagem estão alicerçadas em três matrizes: a matriz verbal, a matriz visual e a matriz sonora. A autora ressalta que seu objetivo não é enfatizar o modo de aparição das mensagens, ou seja, os suportes e canais veiculadores das mensagens, senão a própria constituição dos processos sígnicos possibilitada pelas matrizes. Santaella (2009) ainda afirma que a regra da linguagem, especialmente com a hibridização proporcionada pelas tecnologias de hipermídia, é a mistura, cada vez mais acentuada, dos diferentes tipos de linguagens, e que essa hibridização atua como propulsão para o crescimento das linguagens. Nesse sentido, a autora propõe uma visão interativa e intersemiótica das linguagens.

A proposta das três matrizes da linguagem e pensamento está baseada nas categorias fenomenológicas propostas por Peirce, refletidas nas subdivisões que cada matriz comporta. Santaella (2009) expõe que seu objetivo não é explorar de forma específica os elementos de cada uma das linguagens, mas, sim, evidenciar os fundamentos lógicos e semióticos gerais que regulam suas combinações. Dessa forma, a autora elabora um diagrama em que cada matriz sofre divisões e subdivisões, segundo sua correspondência com as tricotomias do signo de Peirce.

A matriz sonora está para a primeiridade (relações de mera qualidade, possibilidades), no entanto, carrega relações com a secundidade e terceiridade, constituindo-se, assim, o som no domínio do quali-signo, icônico, remático. A matriz visual está para a secundidade

\footnotetext{
${ }^{1}$ Disponível em: <http://buscatextual.cnpq.br/buscatextual/visualizacv.do?id=K4780571J1>. Acesso em: 18 out.
} 2012. 
(que carrega relações físicas entre existentes), tendo, também, relações de primeiridade e terceiridade, constituindo-se no domínio do sin-signo, indicial, dicente. A matriz verbal, por sua vez, está para a terceiridade, no domínio do legi-signo, simbólico, argumental. Ficam claras, assim, as relações entre as três matrizes de linguagem de Santaella (2009) e as categorias gerais de Peirce. Santaella (2009) ainda esclarece que as matrizes da linguagem e pensamento objetivam criar um patamar intermediário entre os conceitos peirceanos que têm caráter de abstração muito elevado e as linguagens manifestas, servindo, assim, de mediação entre a teoria peirceana e a semiótica aplicada.

Umberto Eco (1991), em seu "Tratado geral de Semiótica", propõe, partindo de uma crítica à Semiótica de Peirce, conceitos diferenciados que integram, de forma mais específica, o problema dos referentes nos processos semióticos. Na tricotomia peirceana de símbolo (arbitrariamente relacionado com seu objeto), ícone (semelhante ao seu objeto) e índice (fisicamente relacionado com seu objeto), por exemplo, Eco (1991, p. 3) atenta para o fato de que essas classificações são demasiadamente genéricas e "ocultam uma série de funções sígnicas passíveis de segmentação". Ou seja, para o autor, é necessário sim formular uma Semiótica geral, mas que forneça uma definição apropriada a cada tipo de função sígnica e não apenas aos signos de forma genérica.

Nesse sentido, Eco (1991) propõe que a Semiótica possui dois domínios: uma "Teoria dos códigos" e uma "Teoria da produção sígnica". Sendo que a teoria dos códigos dá embasamento ao desenvolvimento de uma semiótica da significação, ou seja, só há sistema de significação e, portanto, códigos, se existir uma convenção social que possibilite a geração da função sígnica (ECO, 1991). Eco (1991) esclarece: a fumaça funciona como signo para fogo desde que exista uma convenção social precedente que associe a fumaça ao fogo, mas se o fogo e a fumaça forem percebidos no mesmo momento, a fumaça já não funciona como signo do fogo. Nesse sentido, o autor aponta que nem toda inferência é um ato semiósico, conforme Peirce afirmava, mas "existem inferências que devem ser reconhecidas como atos semiósicos" (ECO, 1991, p. 12). São os tipos de função sígnica que podem atribuir valor de função semiósica a determinados fenômenos, definindo, por sua vez, o signo

A teoria da produção sígnica fornece o embasamento para o desenvolvimento de uma semiótica da comunicação, em que é possível perceber um processo de comunicação quando a função sígnica é utilizada para produzir fisicamente expressões para diversos fins práticos (ECO, 1991). A expressão física dos signos para fins de comunicação implica que existam requisitos socialmente reconhecidos e codificados. Assim, a diferença entre "Teoria dos códigos" e a "Teoria da produção sígnica", ainda que dialeticamente correlatas, é a oposição "regra vs processo" (ECO, 1991, p. 2).

Eco (1991) esclarece que a Semiótica não pode ser reduzida a uma teoria dos atos comunicativos, mas a uma tipologia mais ampla de fenômenos sígnicos, ao passo que, para o autor, o signo só o é a partir de 
sua participação na semiose, que se dá por meio da interpretação possível de um intérprete possível, assim,

[...] o destinatário humano é a garantia lógica (e não empírica) da existência de significação, ou seja, da existência de uma função sígnica estabelecida por um código [...] Mas igualmente a suposta presença do emitente humano não é de forma alguma garantia da natureza sígnica de um suposto signo (ECO, 1991, p. 11, grifo do autor).

A partir dessas palavras, podemos pressupor que, para Eco (1991), a semiose ocorre de fato somente a partir da possibilidade do continuum da significação, o signo, assim, não o é por sua própria natureza ou por relação com o seu objeto.

Pensamos ser relevante lembrar ao leitor que todos os autores citados nesta sessão têm contribuições de complexidade e riqueza muito mais amplas do que os conceitos aqui expostos e discutidos. No entanto, acreditamos que estas brevíssimas linhas, podem, ainda assim, apoiar o leitor no momento da análise dos resultados desta pesquisa, fornecendo uma pequena base de reflexão a respeito das relações entre a Semiótica e a CI.

\section{Procedimentos metodológico}

A pesquisa se caracteriza como exploratório-descritiva, com tratamento dos dados de forma quanti-qualitativa e adota como método de levantamento de dados a pesquisa bibliográfica. O levantamento de dados foi realizado em periódicos brasileiros da área de Ciência da Informação, de qualis A2 a B2, no período entre 2000 e 2011. Como estratégia de busca, foram levantados artigos que tivessem o termo "semiótica" nos "termos indexados" ou nas "palavras-chave" do artigo.

Os artigos levantados foram fichados em uma base de dados desenvolvida no Microsoft Access, compreendendo as informações de publicação (periódico, título, autores, ano, etc.) e informações de conteúdo.

\section{Resultados e discussão}

$\mathrm{Na}$ pesquisa bibliográfica, foram recuperados 15 artigos, conforme Quadro 2.

Quadro 2 - Número de artigos recuperados por periódico

\begin{tabular}{|l|l|c|}
\cline { 2 - 3 } \multicolumn{1}{c|}{} & \multicolumn{1}{|c|}{ Periódico } & $\begin{array}{c}\text { Número de artigos } \\
\text { recuperados }\end{array}$ \\
\hline \multirow{2}{*}{ A2 } & Ciência da Informação & 4 \\
\cline { 2 - 3 } & Perspectivas em Ciência da Informação & 0 \\
\hline B1 & Informação e Sociedade & 0 \\
\hline
\end{tabular}




\begin{tabular}{|l|l|c|}
\hline \multirow{4}{*}{ B2 } & Transinformação & 1 \\
\cline { 2 - 3 } & DataGramaZero & 3 \\
\cline { 2 - 3 } & Encontros Bibli & 7 \\
\hline
\end{tabular}

Fonte: Dados da pesquisa.

O Gráfico 1 mostra a recuperação de artigos por ano de publicação, no qual é possível perceber que, em 2006, observa-se o maior número de artigos publicados. Esse fato dá-se, pois, neste ano, a revista Encontros Bibli publicou uma edição especial sobre Semiótica e Ciência da Informação, abrindo um espaço especificamente para a discussão das vias de estudo destas áreas de conhecimento.

Gráfico 1 - Número de artigos recuperados por ano

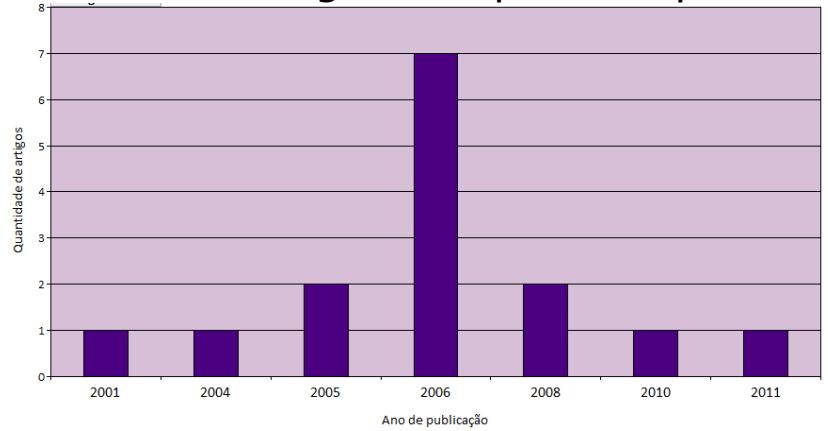

Fonte: Dados da pesquisa.

Em um primeiro olhar, evidenciando que uma busca que abrangeu dez anos de publicação, recuperou-se apenas 15 artigos sobre o tema e, assim, afirma-se que a inserção dos estudos da Semiótica na área da Ciência da Informação ainda é pequena. Para Moreira (2006), a pequena expressividade dos estudos que associam informação ao signo pode estar relacionada à forte adoção da CI à concepção de informação baseada na Teoria Matemática da Comunicação de Claude Shannon e Warren Weaver, em que o signo não é passível de armazenar informação e, portanto, também não pode ser responsável pela sua comunicação. A autora discorre seu argumento em que o signo pode sim armazenar informação uma vez que, se este signo representa um objeto, ele deve expressar de alguma forma características relacionadas a esse objeto. Nesse aspecto, 0 signo comporta informações passíveis do processo de significação pelo interpretante, que reconhece o objeto representado.

Monteiro (2006, p. 43) expõe que "a Linguística, a Semiologia e outras semióticas estruturalistas, como a greimasciana", contextualizam seus estudos de forma hermenêutica, sendo mais amplamente adotados como subsídios de estudos no âmbito da CI. Já a Semiótica de Peirce, postula uma análise fundamental e geral baseada na Lógica e Fenomenologia para análise e classificação de qualquer tipo de signo.

Podemos, no entanto, observar esse campo de estudo dentro da CI como novo e desafiador tendo, portanto, muitos caminhos de pesquisa a oferecer para a área. Cabe aos que se dediquem à exploração e descoberta desses caminhos, apontarem aqueles que podem mais contribuir à CI. 
Nesse sentido, apontaremos agora resultados que mostram que perspectivas da Semiótica foram exploradas nos artigos levantados na construção da reflexão sobre os objetos da CI.

O gráfico 2 aponta a quantidade de artigos que citam autores que estudam a Semiótica.

Gráfico 2 - Autores citados ligados a abordagem de conceitos da semiótica

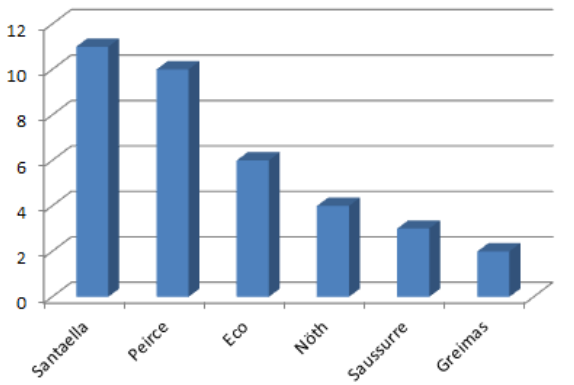

Fonte: Dados da pesquisa.

Santaella aparece como a autora mais citada dentre os artigos, no entanto, apenas uma publicação (ABREU; MONTEIRO, 2010) aborda diretamente sua teoria das matrizes de linguagem e pensamento, buscando categorizar mecanismos de busca na Web, a partir de sua correspondência com a fenomenologia e a semiótica das matrizes da linguagem. As demais citações se referem às abordagens de Peirce, citadas por meio das publicações de Santaella, ou de alguns conceitos postulados pela autora, fundamentalmente baseados em Peirce. De fato, pode-se observar que as abordagens da autora esclarecem, exemplificam e trazem comentários que clarificam a teoria de Peirce. De forma não surpreendente, Peirce comparece como o segundo autor mais citado, entretanto, poderíamos considerá-lo como o autor mais influente da teoria Semiótica na $\mathrm{CI}$, entendendo, como abordado anteriormente, que seus estudos foram citados também por meio de Santaella.

Apenas um artigo não cita, em nenhum momento, os autores Peirce e Santaella. Barbalho (2006a) adota os conceitos semióticos principalmente de Greimas, quando afirma que a linguagem é um sistema constituído socialmente e que as manifestações textuais podem se manifestar de diferentes maneiras. A partir desses conceitos, o autor apresenta uma análise de como a expressão do espaço concreto da biblioteca cria diferentes significados no imaginário coletivo e individual.

É importante observar que outros autores relacionados à discussão da Semiótica, foram citados nos artigos, além daqueles do gráfico. No entanto, a título de delimitação do critério de análise, consideramos as citações mais representativas dos autores que estão relacionados aos fundamentos da Semiótica.

No que concerne à temática semiótica, mais de $60 \%$ dos artigos abordam a teoria da tricotomia do signo de Peirce, sendo que quase todos os artigos abordam a noção da significação ad infinitum, postulada, 
também, por Eco (1991). A classificação dos signos é de fato o aspecto da filosofia e semiótica de Peirce que mais se difundiu e encontrou espaços de análise e aplicação (SANTAELLA, 2009; ALMEIDA, 2009). Sua proposta de classificação geral e fundamental permite a flexibilização da abordagem semiótica em diferentes contextos. O gráfico 3 ilustra esse aspecto.

Gráfico 3 - Tipos de informação abordadas nos artigos

Fonte: Dados da pesquisa.

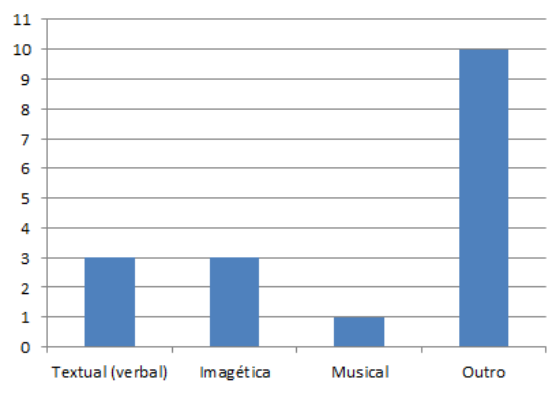

Alguns artigos abordam mais de um tipo de informação, como é o caso de Abreu e Monteiro (2010) que investigam as matrizes verbal, visual e sonora de Santaella, e, vale citar, é o único artigo que aborda a informação musical. Mas, ao olharmos para o gráfico 3, o que chama a atenção é a grande barra azul que se encontra acima daquilo que é classificado como "outro". De fato, as abordagens são diversas, o que fez com que esse aspecto ficasse em evidência. Pois, explicitemos o "outro": a) 3 artigos exploram os conceitos semióticos de forma geral, sem se referir a nenhum tipo de informação específico (AZEVEDO NETTO, 2008a; PEREIRA; BUFREM, 2005; MOURA, 2006); b) 1 artigo aborda a informação gerencial sem indicar se esta se apresenta como textual, imagética, etc. (CÂNDIDO; VALENTIM; CONTANI, 2005); c) 1 artigo aborda a memória virtual em nível conceitual (MONTEIRO; CARELLI; PICKLER, 2006); d) 2 artigos se dedicam a relacionar os conceitos semióticos aos conceitos de informação e conhecimento (MONTEIRO, 2006; MOREIRA, 2006); e e) outros 3 artigos exploram tipos diferenciados de informação: patrimônio arqueológico (AZEVEDO NETTO, 2008b); análise do espaço concreto (BARBALHO, 2006a); imagem da profissão e profissional bibliotecário (BARBALHO, 2006b).

A abordagem mais próxima da prática pode ser verificada em Cândido, Valentim, Contani (2005), Abreu, Monteiro (2010), Azevedo Netto e Freire (2004). Assim, observamos que pelo menos 6 artigos (40\%), inserem as bases semióticas em nível de discussão conceitual e não aplicada. Ainda que os demais artigos também possam ser inseridos em um âmbito conceitual, mas se aproximando mais de uma semiótica aplicada em âmbito de análise mais específica, como no caso daqueles artigos que explicitam o tipo de informação a que se referem.

No que concerne aos temas relacionados à área de CI, 9 artigos (60\%) abordam a organização e representação do conhecimento e da informação. Para tal análise dos artigos, tomou-se por base os conceitos de organização e representação do conhecimento e da informação propostos por Bräscher e Café (2010) que postulam que a organização do 
conhecimento (OC) é um "processo de modelagem do conhecimento que visa a construção de representações do conhecimento [RC]" (BRÄSCHER; CAFÉ, 2010, p. 95, grifo nosso), estas, por sua vez, se concretizam como os sistemas de organização do conhecimento ou linguagens documentárias. O conhecimento, nesse sentido, está ligado ao campo das ideias, às atividades humanas de reconhecimento do mundo exterior por meio da internalização, categorização e classificação de objetos e conceitos em nível cognitivo.

Já o conceito de organização da informação (OI), segundo Bräscher e Café (2010), está vinculado aos processos que envolvem a descrição física e de conteúdo de documentos, gerando produtos como referência bibliográfica, índices e resumos, que são a representação da informação (RI). Ainda que, nos artigos analisados, esses conceitos não estejam tão claros, essa foi a base conceitual utilizada para a classificação dos temas.

A representação do conhecimento e da informação resulta em produtos que se relacionam com objetos, no sentido peirceano. Ou seja, representar significa reapresentar algo, apresentar a coisa por meio de alguma entidade de representação, essa abordagem se aproxima do conceito de signo (MONTEIRO; CARELLI; PICKLER, 2006).

Observamos discussões sobre os conceitos de informação e conhecimento, algumas vezes relacionando o conceito a algum dos tipos de signo de Peirce. Para Moreira (2006), a informação é um índice, pois mantém uma relação referencial com o conhecimento. Em uma perspectiva próxima, Monteiro (2006) afirma que a representação da informação é indicial, sendo que "um sumário, um descritor, um catálogo, uma referência expressam essa relação, seja física ou referencial" (MONTEIRO, 2006, p. 51). Na citação de Monteiro (2006) é possível perceber uma retomada do conceito de RI.

As linguagens documentárias (LD) são, diversas vezes, associadas aos processos semióticos de significação e de representação dessa significação, por meio de um sistema. De forma mais explícita, Lara (2006, p. 26) indica que, de fato, as LDs são sistemas semióticos, pois "a LD funciona como interpretante ou conjunto de interpretantes que são desencadeados por referência a subconjuntos especializados dentro da linguagem geral $[\ldots]^{\prime \prime}$.

De forma mais geral, os artigos abordam os conceitos da Semiótica como pano de fundo nas discussões que englobam os processos de significação tanto por parte dos profissionais da $\mathrm{CI}$, no processo de segmentação do conteúdo para a construção de representações do conhecimento e da informação, como no processo de significação que afeta o usuário no momento de interagir com os sistemas de busca (TOUTAIN et al., 2011; AZEVEDO NETTO, 2008a; LARA, 2001; MOURA, 2006). Essas questões são fortemente relacionadas com a construção de conceitos como processo de reconhecimento e significação da realidade.

Nesse aspecto, fica mais evidenciado o processo de significação ilimitada, considerando-se que a significação da realidade, transposta para o sistema de representação do conhecimento, é novamente significada no momento de representação da informação, esta é significada, então, pelo 
usuário, no momento da busca, que lhe permite relacionar a um objeto de informação e, a partir dai, começa a ocorrência de mais um ciclo de significação.

\section{Conclusão}

A abordagem semiótica na CI é bastante difusa, no entanto, parece ser justamente esse o objetivo dessa ciência quando os autores a colocam como uma ciência geral (ECO, 1991; PEIRCE, 1995; SANTAELLA, 2009). A Semiótica apresenta-se como uma teoria de fundamentos de análise bem amplos, podendo, assim, sofrer diferentes contextualizações e aplicações em maior ou menor profundidade e especificidade. Por outro lado, a Semiótica aborda com propriedade os processos de significação, em que, na $C I$, são mais proeminentes nas atividades relacionadas à organização e representação do conhecimento e da informação, especialmente no que se refere à informação a que a Linguística, com seu enfoque no signo verbal, não explora em sua totalidade, ou seja, a informação visual e sonora e, também, os próprios conceitos de conhecimento e informação.

Entretanto, ainda que provindas de bases teórico-metodológicas diferentes, nem sempre a Semiótica e a Linguística se mostram divergentes. O que vale ressaltar é que a Semiótica pode aprofundar o conhecimento da CI nas informações visuais e, especialmente, musicais, em que os fundamentos teóricos são menos sólidos e pouquíssimos consolidados e, mais ainda, onde não há uma ciência com a especificidade da Linguística, por exemplo, para sua análise no âmbito da significação.

No que concerne à Semiótica da imagem ou matriz visual, como sistema semiótico de comunicação, ela se encontra em desenvolvimento mais sólido, pois os sistemas visuais são mais fortemente institucionalizados (ECO, 1991) em âmbito social, especialmente por meio da área publicitária. Esses estudos preconizam subsídios para a análise dos elementos da imagem na veiculação da informação, que podem e são aplicados na análise da informação imagética, desde a perspectiva da análise documentária da CI (AUGUSTÍN LACRUZ, 2006).

Já a Semiótica musical é um tema que está em desenvolvimento na área da Música (MARTINEZ, 1993; SANTAELLA, 2009), e, ao que parece, em um olhar inicial, está intimamente relacionada com os conceitos fundamentais da musicologia. Apontamos, portanto, para esse que consideramos um promissor percurso de pesquisa na $\mathrm{CI}$ : a semiótica da música na exploração e aplicação de conceitos que fundamentem os princípios de significação da música tanto em nível emocional, corporal como intelectual (MORAES, 1983), perpassando ouvintes, intérpretes e compositores especialistas e leigos. Conceitos esses que podem formar um patamar inicial de propulsão do desenvolvimento da pesquisa em informação musical na CI.

Com base nessas observações, concluímos que a Semiótica se confirma como ciência cuja interdisciplinaridade com a CI é desejada, e, ainda que esteja em desenvolvimento inicial, pode ampliar o horizonte de pesquisa e de desenvolvimento de um arcabouço teórico para a CI 


\section{Referências}

ALMEIDA, C.C. Peirce e a organização da informação: contribuições teóricas da

Semiótica e do Pragmatismo. Marília, 2009. 416f. Tese (Doutorado em Ciência da Informação) - PPGCI- Faculdade de Filosofia e Ciências, UNESP, 2009.

AUGUSTÍN LACRUZ, M. C. Análisis documental de contenido del retrato pictórico. Cartagena: Consejalía de Cultura, 2006.

BARBALHO, C, R. S. Fazer semiótico: subsídios para exame do espaço concreto. Encontros Bibli, Florianópolis, $2^{\circ}$ número esp., $2^{\circ}$ sem. $2006 a$. ECO, U. Tratado geral de semiótica. 2. ed. São Paulo: Perspectiva, 1991. MARTINEZ, J. L. Uma possível teoria semiótica da música (pautada logicamente em Charles Sanders Peirce). Cadernos de estudo: análise musical, São Paulo, n. 5, 1993.

MORAES, J. J. O que é música. São Paulo: Brasiliense, 1983. (Coleção Primeiros Passos).

NÖTH, W. Panorama da semiótica de Platão a Peirce. 4. ed. São Paulo: Annablume, 2003.

PEIRCE, C. S. Semiótica e filosofia. São Paulo: Cultrix, 1972.

PEIRCE, C. S. Semiótica. 2. ed. São Paulo: Perspectiva, 1995.

SANTAELLA, L. A percepção. São Paulo: Experimento, 1993.

SANTAELLA, L. Matrizes da linguagem e pensamento: sonora, visual, verbal. 3. ed. São Paulo: Iluminuras, 2009.

SANTAELLA, L. O que é semiótica. São Paulo: Brasiliense, 1983. (Coleção Primeiros Passos).

SAUSSURE, F. Curso de linguística geral. 7. ed. São Paulo: Cultrix, 1975. VOLLIS, U. Manual de semiótica. São Paulo: Edições Loyola, 2000.

\section{REFERÊNCIAS DO CORPUS DE PESQUISA}

ABREU, J. G.; MONTEIRO, S. D. Matrizes da linguagem e a organização virtual do conhecimento. Ciência da Informação, Brasília, v. 39, n. 2, p. 926, maio/ago. 2010.

AZEVEDO NETTO, C. X. A abordagem do conceito como uma estrutura semiótica. TransInformação, Campinas, v. 20, n. 1, p. 47-58, jan./abr. 2008a.

AZEVEDO NETTO, C. X. Preservação do patrimônio arqueológico: reflexões através do registro e transferência da informação. Ciência da Informação, Brasília, v. 37, n. 3, p. 7-17, set./dez. 2008b.

AZEVEDO NETTO, C. X.; FREIRE, B. M. J.; PEREIRA, P. A representação de imagens no acervo da Biblioteca Digital Paulo Freire: proposta e percursos. Ciência da Informação, Brasília, v. 33, n. 3, p. 17-25, set./dez. 2004.

BARBALHO, C. R. S. Fazer semiótico: subsídios para exame do espaço concreto. Encontros Bibli, Florianópolis, $2^{\circ}$ número esp., $2^{\circ}$ sem. $2006 a$. 
BARBALHO, C. R. S. Regimes de visibilidade das práticas do profissional bibliotecário. Encontros Bibli, Florianópolis, n. esp., $1^{0}$ sem. 2006b.

CÂNDIDO, C. A.; VALENTIM, M. L. P.; CONTANI, M. L. Gestão Estratégica da Informação: semiótica aplicada ao processo de tomada de decisão. DataGramaZero, Rio de Janeiro, v. 6 n. 3, jun. 2005.

LARA, M. L. G. É possível falar em signo e semiose documentária? Encontros Bibli, Florianópolis, $2^{\circ}$ número esp., $2^{\circ}$ sem. 2006.

LARA, M. L. G. O Unicórnio (o Rinoceronte, o Ornitorrinco ... ), a Análise Documentária e a Linguagem Documentária. DataGramaZero, Rio de Janeiro, v.2 n.6, dez. 2001.

MONTEIRO, S.D. Semiótica Peirceana e a questão da informação e do conhecimento. Encontros Bibli, Florianópolis, $2^{\circ}$ número esp., $2^{\circ} \mathrm{sem}$. 2006.

MONTEIRO, S. D.; CARELLI, A.; PICKLER, M. E. Representação e memória no ciberespaço. Ciência da Informação, Brasília, v. 35, n. 3, p. 115-123, set./dez. 2006.

MOREIRA, S. O ícone e a possibilidade de informação. Encontros Bibli, Florianópolis, $2^{\circ}$ número esp., $2^{\circ}$ sem. 2006.

MOURA, M. A. Ciência da Informação e Semiótica: conexão de saberes. Encontros Bibli, Florianópolis, $2^{\circ}$ número esp., p. 1-17, $2^{\circ}$ sem. 2006.

PEREIRA, E. C.; BUFREM, L.S. Princípios de organização e representação de conceitos em linguagens documentárias. Encontros Bibli, Florianópolis, n. 20, p. 21-37, 20 semestre de 2005.

TOUTAIN, L. M. B. et al. Semiótica e produção de sentido. DataGramaZero, Rio de Janeiro, v. 12, n. 1, fev. 2011. 